\title{
Aziridine and $\beta$-Lactam Synthesis by Amination and Carbonylation Reactions
}

Gategory

Synthesis of

Heterocycles

Key words

aziridines

$\beta$-lactams

C-H activation<smiles>CC(C)CC1(C)NC(C)(C)COC1=O</smiles><smiles>CC1(C)CC2(CC(C)(C)N1)OCCO2</smiles>

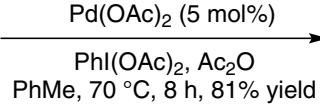

$\mathrm{Pd}(\mathrm{OAc})_{2}(10 \mathrm{~mol} \%)$ $\mathrm{CO} / \mathrm{air}(1 \mathrm{~atm})$

$\mathrm{Cu}(\mathrm{OAc})_{2}(10 \mathrm{~mol} \%)$ $\mathrm{PhMe}, 120^{\circ} \mathrm{C}, 22 \mathrm{~h}, 84 \%$ yield
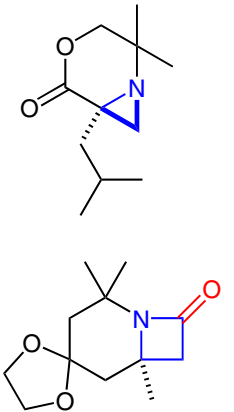

Significance: Although significant progress has been made in the functionalization of unactivated $\mathrm{C}-\mathrm{H}$ bonds, the transformation of aliphatic $\mathrm{C}-\mathrm{H}$ bonds remains a challenging endeavor $(H$. M. L. Davies et al. Chem. Soc. Rev. 2011, 40, 1855). Typically, such transition-metal-catalyzed reactions utilize a directing group within the substrate, which serves to position the metal catalyst in the proximity of a particular $\mathrm{C}-\mathrm{H}$ bond, and proceed through the kinetically favored five-membered cyclometalated intermediate (L. Ackermann Chem. Rev. 2011, 111, 1315). The current report highlights a different mode of reactivity with the reaction being directed by a simple secondary amine and proceeding through a strained four-membered cyclometalated intermediate. A broad substrate scope is demonstrated for the efficient syntheses of a series of aziridines. In addition, the ring opening of these products provides a range of secondary amines presenting substitution patterns which would be difficult to access by more conventional methods. The methodology was extended to incorporate a palladium-mediated $\mathrm{C}-\mathrm{H}$ carbonylation to allow access to potentially biologically active $\beta$-lactams.
Comment: 3,3,5,5-Tetramethylmorpholin-2-one was initially utilized as the model substrate given that this presents a range of $\mathrm{C}-\mathrm{H}$ bonds that cannot participate in the classical five-membered cyclopalladation. Treatment with stoichiometric $\mathrm{Pd}(\mathrm{OAc})_{2}$ led to the isolation of the four-membered ring complex (characterized by $\mathrm{X}$-ray) resulting from the amine-directed cyclopalladation. Oxidation of this intermediate with $\mathrm{Phl}(\mathrm{OAc})_{2}$ led to the formation of the corresponding aziridine through reductive elimination from a palladium(IV) intermediate. Optimization enabled the reaction to be carried out in a catalytic manner. A broad substrate scope was shown demonstrating excellent selectivity for the formation of the strained heterocycles and the ability to differentiate between methyl groups based on subtle stereoelectronic effects. Replacement of the oxidant Phl(OAc) 2 with $\mathrm{CO}$ allowed the development of a carbonylation process proceeding through a palladium(II)palladium(0) catalytic cycle enabling the synthesis of $\beta$-lactams for a range of cyclic and acyclic amines. 